\title{
PRACTICAL KNOWLEDGE AS KNOWLEDGE OF A NORMATIVE JUDGMENT
}

\author{
ERIC MARCUS \\ Auburn University \\ Department of Philosophy \\ 51 W Thach Concourse, Auburn, AL 36849, \\ U.S.A. \\ ericarthurmarcus@gmail.com
}

\author{
Article info \\ CDD: 121 \\ Received: 31.07.2018; Accepted: 23.08.2018 \\ DOI: http://dx.doi.org/10.1590/0100- \\ 6045.2018.V41N4.EM
}

\section{Keywords:}

Practical Knowledge

Anscombe

Memory

The Nature of Action

Practical Reasoning

\begin{abstract}
According to one interpretation of Aristotle's famous thesis, to say that action is the conclusion of practical reasoning is to say that an action is a judgment about what to do. A central motivation for the thesis so understood is that it explains the non-observational character of practical knowledge. If actions are judgments, then whatever explains an agent's knowledge of the relevant judgment can explain her knowledge of the action. I call the approach to action that accepts Aristotle's thesis so understood Normativism. There are many reasons to doubt Normativism. My focus in this paper is a pair of arguments that purport to show that a normative judgment could not constitute an event in material
\end{abstract}


reality and also the knowledge of such a happening. Both highlight a putative mismatch between the natures of, on the one hand, an agent's knowledge of her normative judgment and, on the other, her knowledge of her own action. According to these objections, knowledge of action includes (a) perceptual knowledge and (b) knowledge of what one has already done. But knowledge of a normative judgment includes neither. Hence knowledge of action cannot simply be knowledge of a normative judgment. I show why these arguments fail.

According to one interpretation of Aristotle's famous thesis, to say that action is the conclusion of practical reasoning is to say that action is itself a judgment about what to do. ${ }^{1}$ There are various reasons why one might find this idea appealing. It is natural to think of an action as the agent's answer-perhaps even her most honest answer-to the question "what should I do?". This would explain why we suspect a lack of candor when someone claims to hold that a certain action is, all things considered, what one should do, and yet fails to do it. And an action, like a judgment whether to perform it, is supported or undermined by reasons for thinking one should or should not perform it. An action can be explained by a reason for action no less directly than such a reason can explain a judgment about what to do. The thesis thus promises to reveal actions as themselves moves in the space of reasons. Another motivation for the thesis is that it suggests a path

1 See, e.g., Davidson 1980, Rödl 2007, Tenenbaum 2007, Thompson 2008 and Marcus 2012. McDowell 2010 argues for a non-normativist interpretation of Aristotle's thesis and claims (though I remain unconvinced) Anscombe 2000 as a precursor. 
for understanding the non-observational character of practical knowledge. If actions are judgments, then whatever explains an agent's knowledge of the relevant judgment can explain her knowledge of the action. I will call the approach to action that accepts Aristotle's thesis so understood Normativism.

There are also many reasons to doubt Normativism. Some have to do with whether there can be an intentional action (hereafter, simply 'action') without the relevant judgment. For example, one might hold that an akratic performs an action despite thinking it is, all things considered, precisely what one should not do. And one might doubt whether someone's having made a judgment could plausibly be said to entail the performance of any non-mental action. Even putting aside prior intentions, that entailment would appear to be contradicted by cases in which I intend to do something but my plan for doing it is fundamentally flawed, as were I to judge that swimming to the moon is the thing to do. One might worry that bodily actions have a kind of ontological thickness and particularity that cannot intelligibly be said to correspond to any features of a judgment. Many complain that this sort of view entails an implausible discontinuity between rational and non-rational animals and also between preverbal and verbal phases in the lives of individual rational animals. There are, additionally, reasons for doubting that the performance of an intentional action by a normal adult human is necessarily tied to knowledge of what she is doing. The self-deceived agent, for example, might seem to be unaware of what she is intentionally doing. ${ }^{2}$

It is a pair of objections of this last form with which I am concerned in this essay. But unlike the objection from self-deception, they challenge the idea that, even in

${ }^{2} \mathrm{I}$ address this objection to Normativism in Marcus, ms. 
paradigmatic cases, a normative judgment could at once constitute an event in material reality and also the knowledge of such a happening. Both highlight a putative mismatch between the natures of, on the one hand, an agent's knowledge of her normative judgment and, on the other, her knowledge of her own action. According to these objections, knowledge of action includes (a) perceptual knowledge and (b) knowledge of what one has already done. But knowledge of a normative judgment includes neither. Hence knowledge of action cannot simply be knowledge of a normative judgment.

I will begin, in section I, with a brief sketch of what I take to be the two key motivations for Normativism, followed in sections II and III, by a response to the objections from perception and knowledge of past action.

\section{TWO GAPS}

Normativism is staked on the rejection of two gaps: the gap between what reasons for action explain and the action itself; and the gap between what we know in acting and knowledge of the action itself. I'll call these the 'Reasons Gap' and the 'Knowledge Gap'. The tenability of Normativism depends first on showing that it is a desideratum of a theory of action that it should reject them, and second on successfully avoiding them. Other than my very brief characterization in what immediately follows here, I shall have little to say about the Reasons Gap. But the paper as a whole can be understood as an attempt to show both how Normativism closes the Knowledge Gap and why this is a good thing.

First, the Reasons Gap: Normally (or so I claim) we conceive of our reasons for action as going all the way to the action itself. That is, when I conceive of myself as acting for reasons, I conceive of my reasons as reasons for 
doing what I'm actually doing. This sounds like a truism. But according to a common view-what Sarah Paul calls the 'Attitude View' - one's reasons bear directly only on an attitude, e.g., intention, towards an action type, and the relation between the attitude and the action itself is not a matter of reasons at all. ${ }^{3}$ Such a view is all but inevitable so long as one conceives of action as necessarily distinct from judgment. For reasoning in the best-case scenario culminates in a conclusion-which is to say, in a concluding judgment. If the relevant action is understood to be distinct from any conclusion, reasons will be understood as bearing on the action itself only indirectly via whatever the connection is thought to be between conclusion and action.

According to Normativism, on the contrary, insofar as moving my finger, say, is part of the execution of my intention to type this sentence, I have a reason to move my finger in a way that will accomplish this goal, and my moving my finger in just this way is a direct response to that reason. Since an action just is a judgment about what to do, there is no more a gap between the reasons for performing an action and the action itself as between reasons for performing the action and a judgment that it is to-be-performed. I do the very things I'm doing precisely because they are, in light of the various facts that are my reasons for doing them, to-be-done. My judgment of their to-be-done-ness just is my doing them. And so my reasons go all the way to my action.

On to the Knowledge Gap: Normally (or so I claim) part of what we take ourselves to know in acting is the action itself. To say that we know something in acting is to say that such knowledge is inseparable from actingwithout the knowledge, one would not be performing the relevant action. To deny the gap is to say that part of what

${ }^{3}$ See Paul 2013 and her discussion of Enc 2003. 
it is to do something is to know that one is doing it. Acting is, in this sense, essentially self-conscious. An adherent of Aristotle's Thesis can argue that in acting one knows that in which one's reasoning concludes, and since this judgment just is one's action, knowledge of the judgment just is knowledge of the action. What one knows in acting is precisely the action itself.

This approach tethers the elimination of the gap to the datum that serves as the premise in Anscombe's Intention: that we have non-observational, non-inferential knowledge of our action. But the idea of non-empirical knowledge of action, as I will call it, is deeply puzzling-some think untenable. Any view that argues along these lines will thus seem implausible to some precisely because of the apparent impossibility of knowing our actions in the way we know a normative judgment. Some will thereby be motivated to insist on the gap, whereas others will be motivated to close it via a different strategy. Here, then, as with every interesting philosophical issue, disputants disagree not only about how best to explain the data but about what the data are.

The denial of the two gaps will strike some as borderline incomprehensible, as it can sound tantamount to a withdrawal of actions from the natural world. Many hold that science has revealed ours to be a world in which what happens happens only because of blind, mechanistic causation and what can be known can be known only by observation or inference made from the vantage point of my sensory apparatus. The face the world shows uswhether in the form of non-agential happenings among mere things or in the form of our own actions-must, on this view, be understood as the surface of a reality that operates according to its own causal principles and has depths that are hidden from us. The former can seem to entail the Reasons Gap, and the latter the Knowledge Gap. Perplexity about this issue can make it hard even to 
understand Normativism except as the thesis that actions take place inside the brain. As I have discussed elsewhere, this perplexity is sustained in part by a misunderstanding of the nature of the causation that links, for example, someone's walking a dog and her reasons for doing so. ${ }^{4}$ For the most part, I will put aside this issue and focus on defending the epistemological aims and commitments of Normativism.

\section{Perceptual Knowledge}

The Aristotelean thesis on the Normativist interpretation is that action is constituted by a normative judgment. It would follow that were one to have knowledge of a judgment of the relevant form, one would thereby also have knowledge of the corresponding action. And so an explanation of an agent's non-empirical knowledge of the normative judgment would explain her non-empirical knowledge of the action itself. But, by the same logic, if it could be shown that one could not have such knowledge of action, it would follow that an action is not a normative judgment. According to the first objection, knowledge of action consists in part in perceptual knowledge, and since perceptual knowledge is not knowledge of what is to be done, Normativism is false.

It is a familiar point in discussions of Intention that Anscombe herself did not manage to fully clarify the relation between practical knowledge and the perception that guides us in acting. On the one hand, she says that "the class of intentional actions is a subclass" of "the class of things known without observation." 5 But on the other

\footnotetext{
${ }^{4}$ See Marcus 2012, ch. 2.

${ }^{5}$ Anscombe 2000, 13.
} 
hand, when she asks "is it reasonable to say that one 'knows without observation' that one is painting a wall yellow?" even a relatively comprehending and sympathetic reader may be unsure of what her defense of the affirmative reply is. ${ }^{6}$ The powerful temptation is to view the agent's knowledge of her action as based at least partly on perception.

Suppose I am building a Lego model of a penguin when I receive a phone call from my sister. I put down the tip of the left flipper and answer the phone. She asks what I'm doing. It does not seem as if when I answer her: "building a Lego penguin", I base my answer on perception. I do not need to look over at the half-built penguin to know that this is what I'm doing, nor do I need, it seems, to make any inferences to arrive at this knowledge. Hence, the plausibility of the idea that an agent's knowledge of her action is fundamentally non-empirical. However, the performance of the action itself depends on paying close attention to the look of the sculpture as it develops. I must get the colors and the proportions between the body parts roughly right. And adding a Lego itself requires attention to the feel of the fit between the new piece and the existing structure. One listens for the characteristic clicking sound so that one can be sure that it is secure. Without perceptual knowledge, I could not complete the project. Plainly, I rely on perception. Hence, the temptation to hear a nonperception-based answer to my sister's question merely as an expression of knowledge of what I intend. Knowledge of the action itself would seem to require knowledge of something beyond a normative judgment.

On their face, however, these considerations show only that performing the action depends on perceptual knowledge. It does not follow-at least not immediately - that knowledge that one is performing the action is based on perception.

${ }^{6}$ Anscombe 2000, 50. 
One might exploit this opening to defend Normativism as follows: to will the end is to will the means, and contrapositively, to omit to will the means is to omit to will the end. Part of the means of building a Lego penguin is looking carefully as one builds. The failure to do so amounts to the failure to take what I know to be the necessary means to an end. And this logically entails that there is no action of the relevant sort, and so no knowledge of such an action. But from the fact that performing the action entails looking, it does not follow that one knows that one is performing it by looking.

Yet, the objector might reply, in order to know that I am actually doing it (as it seems natural to put it), I rely on perceptual knowledge. If I ask myself whether what I'm now doing is in fact going to result in my ultimately completing the model, I would likely answer in part by adverting to my observations. In this way, an agent's knowledge of her action does seem to be based in part on perceptual knowledge.

But the insertion of the 'actually' changes the subject. To know that I'm actually doing it, I do rely on perceptual knowledge. But 'actually' signals that what's at issue is a judgment that my plan is working or perhaps that my chances of success exceed a certain threshold. It is the sort of judgment that an observer of my action might make; it is a theoretical judgment. When the observer makes such a judgment, she does so against the background understanding that that is what I am up to. Like the observer, I might know that I'm succeeding in x-ing on the basis of observation. But that judgment, like the observer's, presupposes that $\mathrm{x}$-ing is what I'm up to. Normativism holds that there is no gap between what we know in acting and knowledge of the action itself. This knowledge of the action itself, in turn, is knowledge of what the agent is up to. That is: I, the agent, do not know that $\mathrm{x}$-ing is what I am up to on the basis of perception, 
even if I, like the observer, can know that I am actually xing on the basis of perception. I can judge (and know) on the basis of observation that I am succeeding in $\mathrm{x}$-ing, which presupposes that (as I know) I am x-ing. It is the latter knowledge that is non-empirical.

The existence of a Knowledge Gap might be thought to follow from the plausible thesis that knowledge is a belief that is non-accidentally true. ${ }^{7}$ It is widely held that for a belief to be non-accidentally true, it must be safe, i.e., not easily wrong. But observation is required to make a belief that I am x-ing safe, for most instances of $\mathrm{x}$. To see this, I'll switch to a famous (albeit repurposed) example of Davidson's. I may believe that my signature is, via the miracle of carbon paper, being copied on each of the ten sheets of paper below the one on which I write directly. And this is, we will suppose, just what I intend. Suppose I believe I'm signing my name on the tenth copy. Is this belief safe? Not, one might contend, unless I check. Ten sheets are a lot, even for the highest quality carbon. Without checking, there is no safe belief and hence no knowledge. Thus my knowledge is based on perception.

Three responses on behalf of the Normativist are possible. First, it might be argued that if my plan for writing on the tenth sheet is a bad one, then I am not intentionally signing my name to that sheet full stop. My intention-and my action qua intentional-is defective to the degree that my plan is defective. For one's intention to $\mathrm{x}$ by $\mathrm{y}$-ing to be non-defective, one must know that $\mathrm{y}$-ing is a means to x-ing. This condition is not satisfied in our case. According to the first Normativist reply, safety is guaranteed by any plan that is good enough to support intention full stop, and any such plan will (at least in typical cases) call for the acquisition of perceptual knowledge. Such knowledge is a necessary condition for the continued

${ }^{7}$ Schwenkler, ms.

Manuscrito - Rev. Int. Fil. Campinas, v. 41, n. 4, pp. 319-347, Oct-Dec. 2018. 
possession of a non-defective intention, and hence for the non-defective performance of the relevant action. Nonetheless, one does not know one is $\mathrm{x}$-ing on the basis of that perceptual knowledge. This reply, like the next, accepts the safety requirement but argues that it does not undermine Normativism.

The second response is a slight variation on the first. One might argue that even if the knowledge-requirement just articulated on non-defective intention is too strong, it is nonetheless built-in to any intention that one will compensate for any flaws or gaps in one's plan for executing it by checking on one's progress. To act with the intention of x-ing is to be prepared to adjust one's plan in the face of obstacles it would be reasonable to expect. Knowing the unreliability of carbon-paper in transmitting one's signature through that many sheets, one will check to see if one has managed it before one takes oneself to be done. Perception is part of what is required to execute one's intention, but not as a basis for one's knowledge of what one is doing. As in the first reply, safety is guaranteed by the quality of one's intention, not by a supposed perceptual basis of an agent's knowledge of her action.

The third response is to reject the safety requirement outright. After all, it is a descendant of the old 'truthtracking' conception of knowledge, according to which one's belief must, in order to constitute knowledge, track the truth of $\mathrm{p}$ in 'nearby worlds'. Someone whose belief tracks the truth is responsive to the facts, and therefore can be said to know. But this is a species of the "incorrigibly contemplative conception of knowledge" with which Anscombe contrasts practical knowledge. "Knowledge", on the contemplative conception, "must be something that is judged as such by being in accordance with the facts." 8 A belief is judged to be safe in this way: it must be in

8 Anscombe 2000, 57. 
accordance not just with the facts as they stand, but as they might easily have stood. To judge whether a belief is safe, one examines it at each of the nearby worlds and asks: is it in accordance with the facts in this world? But "practical knowledge," Anscombe holds, is, on the contrary, "the cause of what it understands', unlike 'speculative' knowledge, which 'is derived from the objects known'." It is thus a kind of category error to demand that practical knowledge be safe.

Does it follow that where knowledge is practical, it is lucky? No. The agent apprehends what's happening and not by accident. But the explanation is not that she could not easily have been mistaken. Rather it is that she could not easily have failed. That is, to intentionally $\mathrm{x}$ one must have the ability to $\mathrm{x}$, the know-how, which manifests itself in the production of the 'object' in virtue of this know-how. It is not an accident that the agent has practical knowledge of her action insofar as it is not an accident that she is doing what she intends. Her ability and skill underwrite her genuinely having the relevant intention, but her intentionally performing the action is what explains her knowledge of what's happening. Crucially for our purposes, part of the skill involves the judicious use of perception. But this does not change the fact that she possesses knowledge of what she's doing simply in virtue of being the agent, not on the basis of that perception. ${ }^{10}$

\footnotetext{
${ }^{9}$ Anscombe 2000, 87

10 Might one use this non-accidentality to argue that practical knowledge is after all safe even according to this third reply, as was suggested to me by Karl Schafer and David Horst? Safety, according this thought, is just the concept of a kind of modal connection between mind and world; it does not include a specification of a 'direction of fit'-even if it is usually interpreted theoretically. Perhaps this is right: if safety could be understood simply as the requirement that one's knowledge survives the transition (so to speak) to nearby worlds, then we could say that it
} 
It now might be wondered, however, why we should consider the practical form of cognitive contact between an agent and the world a form of knowledge at all, i.e., a species of the same genus whose more well-known species involves tracking the truth. In reply to this challenge, I will point to the following Hyman-esque conception of knowledge. To know that $\mathrm{p}$ is entailed by the ability to $\mathrm{x}$ in light of the fact that p. One has this ability if one, e.g., sees that $\mathrm{p}$, or has it on good authority that $\mathrm{p}$, or possesses irrefutable evidence that $\mathrm{p}$, and so forth. But one can also act in light of the fact that one is $\mathrm{x}$-ing simply by virtue of intentionally $\mathrm{x}$-ing. Someone who cites my building of a Lego penguin in order to explain why I am extending my hand in a certain manner attributes such knowledge to me. ${ }^{11}$ He thinks of my so extending my hand as something I'm doing in light of the fact that I am building a penguin. That I am eligible to perform the means-action in this light is explained simply by the fact that the end-action is what I'm up to. In sum: Insofar as I can act in light of the fact that I'm x-ing, I have knowledge of this fact. Insofar as what explains this knowledge is simply that I am x-ing, this knowledge is practical.

Now, to the second objection.

would encompass both the theoretical requirement that one could not easily be wrong and the practical requirement that one could not easily have failed. Crucially, the safety requirement so understood would still not entail that practical knowledge is based on observation.

${ }^{11}$ Here I follow Hyman 1999 


\section{KNOWLedge OF THE PAST}

Matthias Haase-who like the Normativist is no friend of the Knowledge Gap-has recently formulated a striking objection to Normativism based on our knowledge of the past. ${ }^{12}$ The basic idea, as I understand it, is as follows: the perspective of the agent includes knowledge not simply of what she aims to do in the here and now and general knowledge of how to achieve this aim, but also knowledge of where she is in the process. She knows what has already been done and what remains to be done. This is part of what we know simply in acting and at the same time what accounts for our knowledge of our action. But if knowledge of what one has done is part of practical knowledge, then one's possession of practical knowledge can't simply be a function of one's knowledge about what to $d o$, and hence cannot be constituted by one's knowledge of a normative judgment.

The problem is not simply that an agent's knowledge of her action includes knowledge of the past. Were that the problem, it would be tempting to try to mitigate the damage by dividing this knowledge into two components, a practical component (concerned with what I'm doing right now), and a theoretical component (concerned with what I've already done). Perhaps something of Normativism's original promise could thereby be salvaged. But not even this backstop is available, for the nature of my knowledge of what I've already done has an ineliminably agentive character.

To make this point, I will use Haase's example: I know the spatula is in the drawer because I put it there. This is not a matter of remembering someone putting it in the drawer and then identifying this someone as myself, as I might see someone in a mirror tracking mud into a restaurant

${ }^{12}$ Haase, forthcoming. 
and then identify this someone as myself. Nor is the situation that I recall the spatula being placed in the drawer by a hand as if seen from the angle of a camera placed between the eyes of an agent who happens to have been me, as in some failed experiment in POV filmmaking. It would be crazy to hold that as I act I have distinctively agential knowledge of what I'm doing, but that after I act my memory provides me only with an observer's knowledge. My knowledge of what I did is practical. But it cannot, it seems, be a judgment that the relevant action is to be done.

And now we are in a position to appreciate why our knowledge of what we are currently doing cannot be separated out into practical and theoretical components. Haase makes the point as follows: for what I'm doing right now to be building a Lego penguin, I must already have built some part of it. To be in the middle of doing something, as opposed to being in stasis, is for some part of what I'm doing to already have been done. There is no "I am x-ing" without "I have already done y [in order to $\mathrm{x}]$ ". Plausibly, it would follow that to know that I am in the midst of doing something, I must not only know how things are with me now, but also how things have been. There is no knowledge of my $\mathrm{x}$-ing without knowledge that I have already done $y$ [in order to $\mathrm{x}$ ]. Thus for what I know in acting to be knowledge of what I'm doing, and not just knowledge of a state that obtains throughout the course of my action, it must include knowledge of what I have already accomplished - knowledge, say, that I have already built the penguin's feet. But my knowledge that I built the feet is not knowledge of what is to be done. Nor, according to the 'spatula reasoning' above, can it be theoretical knowledge. It's practical, but not a stance on the question of what to do.

I find Haase's argument compelling and I will, in what follows, simply accept the challenge to Normativism as just 
described. Obviously, if there is a flaw in his argument, so much the better for Normativism. I am convinced, however, that practical knowledge includes knowledge of past action. Normativism had better be able to explain it.

The key, I will argue, is to understand the interaction between practical knowledge and memory. "I did it", in the relevant context, typically means more or less "I remember doing it". "I know the Lego sculpture was completed because I completed it" is roughly equivalent to "I know the Lego sculpture was completed because I remember completing it". "I remember" in the latter does not express anything that wasn't already present in the former. 'Remember' is thus like 'believe' in 'I am arresting him because I believe that he's guilty"-it makes explicit the form of the explanation "I am arresting him because he's guilty". Thus, an account of what it is to remember doing something would resolve the general epistemological question as to the nature of this sort of justification. And if such an account could be derived from the basic Normativist thesis-and I will argue that it can-this would answer Haase's objection.

To begin, we need to review certain features of memory in general. I take the following taxonomy sketched by Michael Martin to be reasonably uncontroversial and not to beg any of the questions important to our discussion here. Martin describes the 'function' of memory in general as the "preservation of cognitive contact", 13 and holds that the variety in the kinds of memory corresponds to what preserving the connection to various objects of that contact require. To preserve cognitive contact with a fact requires that one remain "sensitive to the holding of a certain truth" 14 , and this amounts to knowledge of the fact. To

${ }^{13}$ Martin 2001, 266.

${ }^{14}$ Martin 2001, 263.

Manuscrito - Rev. Int. Fil. Campinas, v. 41, n. 4, pp. 319-347, Oct-Dec. 2018. 
preserve cognitive contact with a material object requires sensitivity to alterations that the object may undergo, otherwise what memory preserves is simply a past apprehension of the object. Memory of past apprehensions is the province of episodic memory. Episodic memory in the first instance preserves cognitive contact with an event that one must initially have experienced either by "perceiving or living through" it. ${ }^{15}$ According to Martin, then, I can know what happened by remembering a happening. This taxonomy will prove useful in what follows.

Suppose you ask me how I know that the house on the corner is purple. I might say: "I saw it this morning on my way to work" or "the owner told me himself". Here, too, memory is part of the form of the answers. I might just as well have said "I remember seeing it this morning on my way to work" or "I remember the owner telling me himself". Memory preserves my apprehension of the seeing and the being told. In so doing, it does not simply keep me in cognitive contact with the fact seen or told, but with the seeing and telling themselves. Hence, I know that the house is purple on the basis of perception in the first case, testimony in the second case. I do not infer from the fact that I have a residual visual image of the house or auditory 'image' of the telling that it is likely that the house is purple. Rather, my memory preserves my perceptual or testimonial connection to the color of the house, even as it is no longer visible or being spoken of. Episodic memory preserves not just what I know, but how I know.

I propose an analogous approach to the interaction of memory and practical knowledge. We should say that the answer "I put it there" to the question "How do you know that the spatula is in the drawer?" expresses the practical knowledge I had at the time of the action's performance.

${ }^{15}$ Martin 2001, 265. 
And if Normativism yields an adequate account of practical knowledge of what I am doing, then, in order to arrive at a Normativist account of what I was doing, we simply need to augment the account in a manner analogous to the way we would accounts of perceptual or testimonial knowledge to allow for their preservation by memory.

There are complications. Normativism is an account of our knowledge of what is not yet done, of what an agent is (in the midst of) doing. An action, according to this approach, is an answer to the question of what to do. It can be as direct an answer to relevant considerations as can a judgment such as "I should assemble the flipper". Assembling the flipper, on this view, just is my representing doing so as to be done. Insofar as I perform an action that is constituted by such a judgment, I face the question of what to do in order to assemble it. I determine, say, that I must find Legos of the appropriate colors and shapes. I am finding Legos that fit the bill because (as I know practically) I am assembling a flipper. Once the flipper is fully assembled, then nothing remains to be done and I am no longer assembling it, and so no longer have practical knowledge of my doing so. Practical knowledge is over when the action is over.

Two problems for my proposal emerge. First, it threatens to make the very idea of preserving practical knowledge via memory incoherent since, on the Normativist picture, practical knowledge is essentially oriented towards the future. Second, insofar as the answer "because I put it there" is understood in terms of memory, it is the memory of having completed an action, not (or not simply) the memory of having been in the midst of completing it. But Normativism seems to have nothing to say about knowledge of completed actions. So even if the first difficulty could be surmounted, it would at best save only practical knowledge of what an agent was doing. This 
is short of what's required: practical knowledge of having done something.

First problem first: If we take seriously the analogy with the memory of seeing and being told, we should say that my knowledge that I was crossing the street is practical because memory preserves the nature of my original, practical justification. My representing $\mathrm{x}$ as what is to be done becomes my representing $\mathrm{x}$ as what was to be done, and thus knowledge that I am x-ing becomes knowledge that I was $\mathrm{x}$-ing. Over the course of this transition, practical knowledge disengages from the will; but I remember what then engaged my will. My remembering doing it is the preservation of my practical knowledge of doing it.

Haase's point is that, strictly speaking, Normativism excludes practical knowledge of past action, since by hypothesis the time for action has lapsed. But if this provided reason for thinking that Normativism could not be augmented in the manner just sketched (and Haase has not suggested that it couldn't be), it would also undermine the view that perceptual and testimonial knowledge could be derived from past perceivings and tellings. Objects of perception are paradigmatically potential objects of interaction. The doorbell I see is available to be rung. When I remember seeing it I remember this availability, but this does not lead me to include ringing it among my current affordances. Similarly, my knowledge that I was crossing the street is a matter of remembering crossing the street as what was then to-be-done. I remember having as my aim getting across and consequently adopting the various means that doing so required. This does not lead me to renew my attempt to cross it. As what's remembered recedes into the past, our relation to the objects of memory changes accordingly, but our knowledge can nonetheless be preserved. Spelling this idea out in detail is a worthwhile 
project, but practical knowledge, even on the Normativist conception, does not pose any special problems for it.

I will suppose that this suffices to show that Normativism can account for an agent's knowledge of what she was doing. But the second problem remains, for knowledge of what I was doing does not seem to get me all the way to knowledge of what I've done, as the latter includes knowledge of the completion of the action. And there is no analogous path to agentive knowledge of the past perfective judgment since, unlike "I was building a Lego penguin", "I built a Lego penguin" lacks a presenttense sense. Since there is no present tense practical judgment, there is no object of such a judgment with which to preserve cognitive contact via memory.

Plainly, there is such a thing as remembering building a Lego penguin. And what is remembered is doing something, an event each of whose phases was at one time present. And I don't simply remember being in the midst of doing it, I remember finishing. I finished building the penguin when, as I remember, the left flipper was attached. There was nothing left to do. But if this is the best that the Normativist can manage, then Haase's challenge remains unmet. For it looks as if the memory of having built the penguin would be some hybrid of remembering being in the midst of doing it - a practical judgment — and a belief, based on perception, that it was in the end done-a theoretical judgment. The Normativist would have failed to explain how "I did it" can express purely practical knowledge of what I did in the way that "I'm doing it" can express practical knowledge of what I'm doing.

I envision three possible replies. First, one might reject the idea that a purely practical judgment is necessary to answer Haase's challenge. Second, one might argue that the judgment that the action was complete is itself a practical judgment. And third, one might argue that it is 
mistake to think that knowledge of completion requires more than knowledge of progress.

Haase's insight is that knowing by doing is a sui generis form of knowledge. I know the spatula is in the drawer because I put it there, where this is not reducible to knowing by any other method-by perception, by ratiocination, testimony, etc. But if knowing that I was putting it there is distinctively practical, then it's not clear why, even if my knowledge that I'm finished is theoretical, my knowledge of the action would not vindicate Haase's formula. After all, practical knowledge is-as became evident in the foregoing discussion of perceptiongenerally facilitated by theoretical knowledge. That I only know to pick up that Lego on the basis of perception does not undermine the practicality of my knowledge that I am building a Lego penguin. Similarly that I know that the model is complete on the basis of perception does not obviously render my knowledge that I built it theoretical. It is just the last in a series of perception-based theoretical judgments on which I rely in performing the action. That is the first possible response.

However it is not even clear that my knowledge that I'm finished is theoretical. To see this, consider that, as Anton Ford among others has recently emphasized, Anscombe's famous 'why?' question asked of the agent by someone else inverts a 'how?' question that the agent (in effect) asks of herself. Whereas the 'why?' question begins with what is, relative to the answers that follow, a question about what a certain action is a means to, the agent begins with an aim and answers "how?" questions in order to arrive at ever more specific means. The unfolding of the action is made up of the agent's answers to a series of how-questions, informed by what has been done already and also what remains to be done. The question "what else needs to be done (to realize x-ing)?" is asked from the point of view of someone who is in the midst of $\mathrm{x}$-ing. If I judge that what 
remains to be done is y-ing, then I am thereby embarked on $y$-ing, and confronted with the question of how to y. The judgment that what remains to be done is y-ing-and so that y-ing is to-be-done-is practical precisely because it is identical to $y$-ing. It is in virtue of making this judgment that one can now answer the question "why are you z-ing" by saying "because I am y-ing". To perform an action is to be ready to incorporate answers to how-questions concerning what is left to do into one's plan for completing it, i.e., to take up the courses of action that are determined by answers to those how-questions. An agent shows that $\mathrm{x}$-ing is an action by granting application to someone else's "why?" question; but equally, she 'shows' that $\mathrm{x}$-ing is an action insofar as "how shall $\mathrm{I} x$ " is a question for her.

But the judgment that there's nothing left to be donethe "I'm finished" judgment, as we might call it-is, plausibly, also practical, even if it is a limiting case. Unlike "he's finished", it is not simply an observation that a certain course of action has come to an end. That someone else has finished may have implications for my own plans and projects, but not simply in virtue of its being her "I'm finished" judgment. Her being finished engages my will conditionally, insofar as my plans and intentions may happen to await her being finished. But the judgment that she's finished does not itself express a modification of my own will. However, my "I'm finished" judgment, no less than my "y-ing remains to be done" judgment, does (or in any case can) express such a modification. Specifically, it articulates my release from any further action in pursuit of what had been an unachieved aim. Just as "no reason" does not show that the "why?" question was misplaced, neither does "nothing" show that the "how?" question was misplaced. The practical orientation towards the facts that constitutes being in the midst of doing something necessarily includes the moment at which the proper response to the facts is to stop: that is a practical judgment 
too. One judges "I'm finished" when one has completed the action, and so no further action in pursuit of the relevant end is called for. Since to remember an "I'm finished" judgment is, according to this argument, to remember a practical judgment, no hybrid of the practical and the theoretical is needed to answer Haase's challenge.

A third tack would be to argue that both of these replies misunderstand the relation between the imperfective and the perfective in relation to action. This thought runs as follows: ${ }^{16}$ for an unfolding event-say the falling to the ground of a tree-to become a completed event, nothing more needs to happen beyond a sufficient quantity of falling-to-the-ground. The completion of an in-progress event does not require a further event; it just requires more falling-to-the-ground. Similarly for the building of a Lego penguin: when enough progress is made, the penguinbuilding is over. But in the case of an action, part of what it is to make progress is to know that one is making progress. Just as completion itself does not require more than more progress, knowledge of completion does not require more than more knowledge of progress. If this is right, it doesn't matter how we resolve the dispute about the "I'm finished" judgment.

The crucial point, according to this third reply, is this: For the present moment to be one at which progress is being made, it must be true that some progress has already been made. To put it in terms of Haase's argument sketched above, any moment at which it is true that I (know that I) am x-ing, it must be true that I (know that I) have $y$-ed (i.e, completed some portion of the $x$-ing). In order to have y-ed, I must have once been y-ing, and thus have had present practical knowledge of my y-ing. Once I have done enough to finish $\mathrm{x}$-ing (and thus to know that I have finished $\mathrm{x}$-ing), I will have practical knowledge not

16 Thanks to Michael Thompson for this thought. 
only of my having been x-ing, but of my having x-ed. Thus normativism can explain how I can have purely practical knowledge of what I'm doing, notwithstanding the fact that this requires me to have knowledge of what I've done: that knowledge is practical too.

I'm inclined to view the third response as a way of supplementing the first. The reason why an observation can be the ground of my stopping without rendering my knowledge of completion theoretical is because it is built-in to the character of the relevant sort of progress that it is facilitated by observation. To make enough of this facilitated-by-observation progress is to complete the action, and so to know (by knowing all of the progress one has made) that one has completed the action. The second reply, though it rests on what I take be an accurate characterization of the "I'm finished" judgment, is thus unnecessary for responding to Haase.

There is a remaining worry about the emerging Normativist account of knowing what one has done. It might seem as if, on this account, what is remembered by someone who built a Lego penguin lacks the unity that such a thing in fact possesses. For all I've said, what I remember might be a disconnected hodgepodge of the various phases of penguin-building and a single moment of finding the penguin fully assembled.

To answer this worry, let us first attempt to answer the corresponding worry about the memory of a perceived event. Suppose I see a tree fall to the ground, and later remember seeing the fall. What I remember is not just the tree at a series of points in between and including standing up on its own and laying on the ground. Perceptual memory is not like an album of snapshots. How precisely to explain the way perception presents the original event as a unity, and how that unity is preserved by memory are important questions for the philosophy of perception. Presumably, a crucial part of the explanation is that my 
experience of the tree falling is intimately connected to my understanding of the event as a causal process. My experience of the connection between each phase of the fall is informed by my seeing each phase as occurring because of the prior one. How literally we should take the relevant sense of 'sees' is not an issue that we can explore here. ${ }^{17}$ The crucial point is that my apprehension of the unity of the event is a function of my seeing or 'seeing' it as a manifestation of a particular species of mechanistic causality.

In the case of an action, my apprehension of the unity of the event is a function of its being my action. What makes it the case that what I'm doing is looking for blocks in order to assemble a flipper, and assembling a flipper in order to build a Lego penguin, is that I represent looking for blocks as to be done in light of the to-be-done-ness of assembling the flipper, and I represent assembling the flipper as to be done in light of the to-be-done-ness of building the penguin. The real unity of the event is nothing other than my representing the relevant means-actions as to be done in light, ultimately, of the end-action. Normativism about individual actions is one piece of a more general doctrine according to which the causal connections between the parts of actions are themselves constituted by normative judgments about how the to-bedone-ness of the end-action confers to-be-done-ness on actions that facilitate the agent's achieving the end. ${ }^{18}$ Furthermore, my knowledge of the unity is itself an aspect of the reality of that unity; it is inseparable from its reality. For those rational-causal connections between the phases of action depend on my having in view my own aims and drawing practical inferences in light of them.

17 Cf. Roessler 2011.

${ }^{18}$ Marcus 2012, chs. 2 and 4. 
My memory of an action is thus not of a series of instants at each of which I found myself closer to reaching an end, finally capped by seeing that the end had been reached. Rather I remember what was, while it was unfolding, always already a unity-one constituted by my possession of the locally governing intention. And this is also how I remember it. Often, if not always, my memory of an action includes the memory of having completed it as a culmination of the various actions taken in support of its end.

\section{CONCLUSION}

By way of conclusion, I return to a very general thought mentioned above, one that underlies the intuition that there must be a gap between what we know in acting and knowledge of our action itself. The action itself, whether conceived of as in-process or completed, has many descriptions. It is, in that sense, ontologically thick. But there are very few descriptions of it under which I know it practically. My building the Lego penguin is also, unbeknownst to me, my angering my daughter, frightening the fish, etc. Even if Davidson was wrong and my action is not identical to any physically describable events, it is identical to the initiation of many such events, e.g., the pushing around of molecules in the area and who knows what else via 'butterfly-effect'. As such, it can seem that, even if the arguments presented in the foregoing are correct, the knowledge of the material world that is thereby secured for Normativism is vanishingly thin. And in this way, it might seem that practical knowledge is not on all fours with theoretical knowledge.

The foregoing discussion enables us to see that this concern is without merit. Knowledge that any event was occurring or occurred will necessarily leave out other 
descriptions of that same event, no matter how it is known. I may know on the basis of perception that a tree is falling or fell without knowing the event under countless other descriptions, e.g., the angering of my daughter, the frightening of the fish, the pushing around of molecules in the area, etc. Furthermore, just as perceptual knowledge that a tree was falling or fell must include, either as a component of the perception or of our uptake of it, some grasp of the causal structure of the event, practical knowledge that I was building or built a Lego penguin must also include knowledge of the event's causal structure. And Normativism provides an explanation of this knowledge. Thus while knowledge of events may well require morethan-superficial understanding of the cement that binds its phases together to form its unified character, our practical knowledge-insofar as it consists in the self-consciousness of the act that constitutes the unifying causation-amounts to the deepest possible knowledge of such a unity. ${ }^{19}$

\section{REFERENCES}

Anscombe, G.E.M. Intention, Cambridge, MA.: Harvard University Press, 2000.

Davidson, D. Essays on Actions and Events, Oxford: Clarendon Press, 1980.

19 Many of the ideas in this paper emerged in response to the work of and in the course of conversations with Matthias Haase. One could view the essay as my portion of a dialogue with him. I also benefited enormously from discussions with the participants in the Agency and Rationality workshop at the University of Campinas in June 2018. 
ENC, B. (2003). How We Act. Oxford: Oxford University Press, 2003.

HAASE, M. (Forthcoming). Knowing by Doing in Beings and Doings, edited by Alexander Geddes and Alec Hinshelwood. Oxford: Oxford University Press.

HyMAN, J. How knowledge works. Philosophical Quarterly 49 (197):433-451, 1999.

Marcus, E. Rational Causation. Harvard University Press, 2012.

(Manuscript). Reconciling Practical Knowledge with Self-Deception.

MARTin, Michael G. F. Out of the past: Episodic recall as retained acquaintance. In Christoph Hoerl \& Teresa McCormack (eds.), Time and Memory. Oxford University Press. pp. 257-284, 2001.

MCDOweLL, J. What is the content of an intention in action? Ratio 23 (4):415-432, 2010.

PAUL, SARAH K. The conclusion of practical reasoning: the shadow between idea and act. Canadian Journal of Philosophy 43 (3): 287-302, 2013.

RöDL, S. Self-Consciousness. Harvard University Press, 2007.

Roessler, J. Perception, Counterfactuals, and Special Causal Concepts. In Christoph Hoerl, Teresa McCormack \& Sarah R. Beck (eds.), Understanding Counterfactuals, Understanding Causation. Oxford University, 2011.

SCHWENKLER, J. (Manuscript). Guide to Anscombe's Intention.

STOUT, R. Practical reasoning and practical knowledge. Canadian Journal of Philosophy, 2018. 
Tenenbaum, S. The conclusion of practical reason. In New Trends in Philosophy: Moral Psychology. Rodopi. pp. 323343, 2007.

Thompson, M. Life and Action. Cambridge, MA: Harvard University Press, 2008.

$(\mathrm{ac}) \mathrm{EY}$ 